\title{
SOBRE LA PASTORELA: A PROPÓSITO DE UNA CANCIÓN NAVIDEÑ̃ ESPAÑOLA EN LAS ISLAS MARIANAS*
}

\author{
PALOMA AlBALÁ \\ Instituto de la Lengua Española. CSIC
}

\section{UN TEXTO ESPAÑOL EN LAS ISLAS MARIANAS}

El archipiélago de las islas Marianas, situado en el Océano Pacífico, al norte del Ecuador y al este de Filipinas, es uno de los puntos más apartados de lo que fue el antiguo dominio hispánico. Las islas Marianas pertenecieron a España desde que la expedición de Magallanes y Elcano - que lograría llevar a cabo la primera circunnavegación del globo- las descubrió en el año 1521. La presencia y administración españolas dieron comienzo en el siglo XVII, se afianzaron durante el XVIII y se prolongaron durante el XIX hasta después de la guerra hispanoestadounidense, momento en que España tuvo que ceder la isla de Guam a Estados Unidos y un año después, vender a Alemania el resto de sus posesiones en Oceanía, entre ellas todas las islas del archipiélago de las Marianas a excepción de Guam que ya era estadounidense.

La presencia permanente y las tareas evangelizadoras comenzaron en las islas Marianas en la segunda mitad del siglo XVII. El hecho de que estas islas fueran parada obligada del galeón de Acapulco, para su avituallamiento, hizo que recibieran una especial atención, puesto que el galeón, en su ida hacia Manila desde Nueva España, se detenía en Guam. Este hecho influyó decisivamente en la historia de las islas, pues, debido a ello obtuvieron siempre una atención privilegiada. En 1668 llegó a Guam a bordo del galeón el jesuita Diego Luis de Sanvitores, con otros cinco misioneros de su orden, para crear la primera misión de las islas que sería el primer asentamiento fijo evangelizador e hispanizador de Oceanía ${ }^{1}$.

* Este artículo forma parte del trabajo que llevo a cabo en el Proyecto Diccionario español e internacional de términos literarios del Instituto de la Lengua Española (CSIC) dirigido por Miguel Ángel Garrido Gallardo.

${ }^{1}$ Sobre la vida de Sanvitores y su labor en las islas Marianas, vid. Francisco GARcía, Vida y martyrio de el venerable padre Diego Luis de Sanvitores de la Compañía de

Rlit, LXIV, 128 (2002), 365-384 
Desde el siglo XVII toda la actividad administrativa, eclesiástica y comercial, se centralizó en Manila. Las Marianas dependieron administrativamente del gobierno de Manila, que a su vez dependía del virreinato de México.

La administración española, el contacto continuado aunque difícil y la presencia de población hispana en las islas hizo que la influencia de todo lo español e hispánico en general, tuviera su eco en las Marianas y hubiera una serie de influencias que todavía hoy podemos rastrear. Un hecho importante fue la eficaz evangelización que se llevó a cabo. De hecho, actualmente la población autóctona, los llamados chamorros, son católicos en su mayoría. La hispanización, sin embargo, fue un objetivo conseguido de forma mucho más precaria. La lengua española no fue nunca lengua materna de ningún grupo de población de las islas ${ }^{2}$ lo que mermó su capacidad de pervivencia.

En el siglo XIX, todavía vigente la administración española, el español se hablaba en las islas y era quizá la lengua más extendida pero quedaba encuadrada en un complejo panorama lingüístico ${ }^{3}$. Era, eso sí, la lengua culta cargada de prestigio que servía para la administración; la enseñan$\mathrm{za}^{4}$, aunque ésta se llevaba a cabo en chamorro en los niveles elementales; el culto, aunque desde siempre la lengua chamorra fue utilizada por los sacerdotes y misioneros, etc. Con el final de la soberanía española, el español fue retrocediendo de forma imparable 5 .

Iesvs...desde el año de mil seiscientos y sesenta y ocho, Madrid, Ivan García Infanzón, 1683. Se puede consultar en el CD-Rom Textos clásicos para la Historia del Pacífico Español, Compilación y estudio introductorio por Paloma Albalá, Madrid, Fundación Histórica Tavera, 2000. (Serie II: Temáticas para la historia de Iberoamérica).

${ }^{2}$ Ello se debió, en gran parte, a la escasísima presencia de mujeres de habla española y a la pobre, en general, presencia de hispanohablantes en las islas.

${ }^{3}$ Sobre estas cuestiones Rodríguez-Ponga concluye: «Durante el siglo XVIII y la primera mitad del XIX se produjo una situación de criollización y de mezcla lingüística. [...] el chamorro primitivo - el protochamorro- desapareció al desaparecer su población natural, a causa, precisamente, de ese intensísimo mestizaje entre personas de los cinco continentes. Lo que se llamaba chamorro en el siglo XIX y hoy se sigue llamando chamorro es una lengua nueva. Y, por su parte, el español -0 ese dialecto peculiar de las islas- se mantuvo como segunda lengua, porque el español era la lengua oficial de la metrópoli, estaba cargada de prestigio y era la lengua materna de la clase dirigente llegada desde España» [Rafael RoDRíGUEZ-PONGA, « ¿Qué se hablaba en las Marianas a finales del siglo XIX?», en Miguel LUQUE y Fernando PALOMO (coord), 1898 España y el Pacífico. Interpretación del pasado, realidad del presente, Madrid, Asociación Española de Estudios del Pacífico, 1999, p. 525].

${ }^{4}$ Vid. Belén POZUelo MASCARAQUE, «El sistema educativo en las islas Marianas en el siglo XIX», en Antonio García ABÁsolo (ed.), España y el Pacífico, Córdoḅa, Dirección General de Relaciones Culturales, Ministerio de Asuntos Exteriores y Asociación Española de Estudios del Pacífico, 1997, pp. 325-342.

5 Vid. Florentino RODAO, «La cultura Española en Oceanía después de 1898», Revista Española del Pacífico, vol. 7, 1997, pp. 31-42. 
Actualmente, el español ha desaparecido en las islas como código de comunicación; sin embargo, quedan algunos restos que testimonian su presencia en siglos anteriores. Aparte de la gran cantidad de palabras españolas que perviven en la lengua autóctona ${ }^{6}$, en las Marianas se siguen conservando oraciones y canciones en español. Una de ellas, que transcribo a continuación, es objeto de análisis en el presente trabajo. Se trata de una canción navideña que recogí y registré en $1985^{7}$ en la isla de Guam, en la de Saipán y en la de Tinián. Posteriormente, en noviembre de 1999, con ocasión de la celebración de la Conferencia Cultural del Asia y Pacífico Hispanos, el grupo de chamorros que asistió a los actos, en una reunión de carácter amistoso en Madrid, cantó la misma canción:

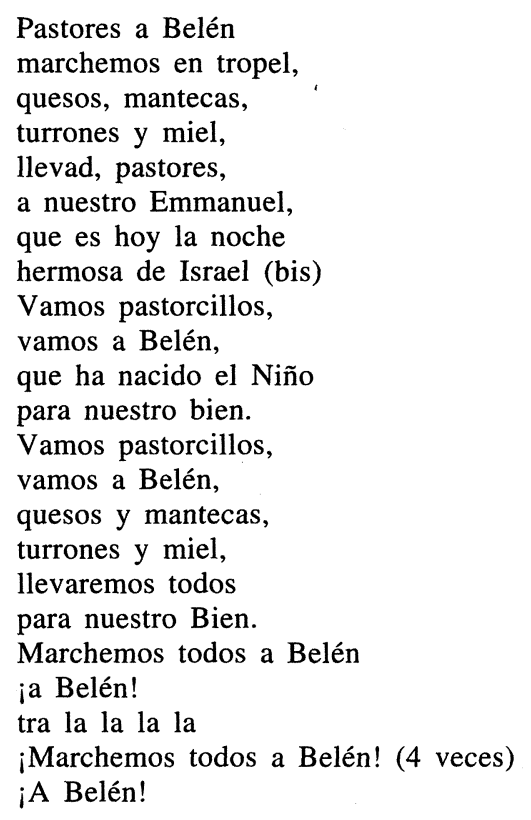

\section{ANÁLISIS MÉTRICO}

Desde el punto de vista métrico, esta canción de tema navideño es un romancillo hexasilábico con asonancia en -é, encabezado por un pareado heptasilábico que sirve de exordio. Existen algunos versos métricamente irregulares como el v.3, el v.5 y el v.7 de solo cinco sílabas. Estas varia-

${ }^{6}$ Vid. Rafael RODRíGUEZ-PONGA, «Islas Marianas», en Manuel Alvar (dir.), Manual de Dialectología Hispánica. El español de América, Barcelona, Ariel, 1996.

${ }^{7}$ En 1985 viajé a las islas Marianas con una beca de la Fundación Juan March y una «Ayuda a la investigación del V Centenario del Descubrimiento». 
ciones pueden explicarse fácilmente por las variaciones propias de un texto de transmisión oral en que el cantor tiene olvidos que soluciona al cantar con un alargamiento de la sílaba allí donde sea necesario.

Además, esos versos irregulares podrían explicarse si pensamos en la posibilidad de que originalmente el v. 3 fuese «quesos [y] mantecas» (como el v. 15); y el v. 5 fuese «llevad [los] pastores». En cualquier caso, esa defectividad de sílabas se soluciona con un alargamiento en el canto. En el v. 8 habría que hacer sinéresis en «Israel»

El romancillo es una variedad del romance, la «creación métrica española más genuina, más sencilla y más difundida» ${ }^{8}$. La utilización de este tipo poemático es enorme durante una época muy extensa de la lírica castellana que incluye el Barroco. Ese intensísimo cultivo hace que aparezcan algunas innovaciones métricas entre las que encontramos los distintos tipos de romancillos, que son romances de metros menores, normalmente de seis o siete sílabas.

El hexasílabo es el tercer metro más frecuente en arte menor. Procede de la poesía medieval latina y lo encontramos en la lírica románica en la poesía provenzal, con el mismo ritmo trocaico que tenía en la poesía latina. Aparece asímismo, en la lírica galaico-portuguesa pero con ritmo dactílico. En la lírica castellana, el hexasílabo se hace frecuente precisamente en romancillos y villancicos ${ }^{9}$. En cuanto al esquema acentual, el hexasílabo lleva siempre el acento en la quinta sílaba, y en el texto que analizamos, abunda el hexasílabo trocaico que tiene además la primera o tercera sílaba tónica. Sólo hay un verso («turrones y miel») que presenta ritmo anfibráquico ${ }^{10}$.

La interpretación de este texto como un romance hexasilábico se corrobora más adelante pues podemos comprobar que varios de los poemas del mismo género que transcribimos tienen la misma forma métrica: así, la canción transcrita en el punto 4 que comienza «hola pastorcillos» es un romance hexasilábico con asonancia en -á y, del mismo modo, el texto atribuido a sor Juana Inés de la Cruz que presenta asonante en -éo y se transcribe en el punto 5. Su primer verso es «Pastores amigos».

La rima de nuestro texto es asonante en -é en los versos pares como corresponde a un romance, asonancia que queda establecida en el pareado inicial. En ocasiones, la rima en -é aparece «reafirmada» por una rima que podría parecer consonante pues hace coincidir al final del verso más sonidos que los vocálicos («tropel, miel, Enmanuel») ${ }^{11}$.

\footnotetext{
${ }^{8}$ Isabel PARAíso, La métrica española en su contexto románico, Madrid, Arco Libros, 2000, p. 160.

${ }^{9}$ Ibid., p. 125

10 Vid. por ejemplo Domínguez CAPARRós, Métrica española, Madrid, Síntesis, 2000, pp. 145-146.

${ }^{11}$ Este hecho podría relacionarse con la rima homeoteleuton u homoteleuton que «produce en ocasiones rimas que vienen a coincidir con nuestra consonante» y que ha sido
} 
Por su sentido, los versos del romance suelen agruparse de dos en dos. En nuestro texto podemos ver cómo esta agrupación binaria de sentido aparece además reforzada por esquemas acentuales exactos: por ejemplo los dos versos heptasílabos que forman el pareado inicial tienen el mismo esquema acentual (-/ - - / - ). El heptasílabo lleva acento en la sexta sílaba de forma preceptiva y además en este caso lleva acento en la segunda, por tanto su ritmo es yámbico ${ }^{12}$. Así también, los versos 9 y 10 («vamos pastorcillos, / vamos a Belén») presentan un mismo esquema acentual (/ - - / -); los versos 11 y 12 que constituyen, asímismo, una unidad de sentido («que ha nacido el niño / para nuestrro bien») presentan un exacto esquema acentual $(--/-/-)$ y lo mismo habría que decir del 17 y del 18 («llevaremos todos / para nuestro Bien») que reproducen los dos el esquema ya señalado para los versos 11 y 12 .

\section{TEXTOS CANTABLES-REPRESENTABLES}

Este tipo de textos de tema navideño tienen la finalidad de ser cantados y también en algún momento, la posibilidad de ser representados. Sabemos que, hasta cierto punto, los villancicos y otras piezas cantables sustituyeron o continuaron la función que tenía el tropo ${ }^{13}$ en la Edad Media como elemento de «diversión» y participación de los fieles en los extensos ritos litúrgicos ${ }^{14}$. Es importante considerar cuál fue la función litúrgica del villancico y cómo a partir del siglo XVI, adquiere una importancia cada vez mayor sustituyendo a los responsorios en los maitines ${ }^{15}$. Encontramos

estudiada en los poemas de influencia semítica (Paloma DíAZ-MAS y Carlos Mota, Introducción a Sem Tob de Carrión, Proverbios morales, Madrid, Cátedra, 1998, p. 49).

${ }_{12}$ Ibid., p. 146.

13 Vid. Fernando LÁZaro Carreter, Teatro medieval, Madrid, Castalia, 1976, pp. 17-18:

«Los tropos ... se desarrollan en medios monásticos suizos y franceses, desde mediados del siglo IX y que pronto se extienden por toda Europa. Son textos breves que se interpolan en un texto litúrgico, bien aprovechando una frase musical sin letra en el canto, bien dotándolos de melodía propia.... Quizá a través de una etapa en que el texto se divide entre las dos mitades del coro, los tropos se hacen decididamente dialogados.... [Cuando] ya existe un texto dialogado o interpretado ante el público por clérigos, que encarnan personajes evangélicos en el seno de las ceremonias sacras, podemos hablar, aunque su extensión sea tan exigua, de auténticos dramas litúrgicos».

${ }_{14}$ «El tropo a menudo tiene forma dramática; $p$. ej. el célebre canto que se ejecutaba antes del Introito durante la misa del día de Pascua. El reparto del diálogo entre varios cantores fue el comienzo de una evolución que concluiría en el drama religioso medieval» (Isabel PARAíso, op. cit. p. 50).

${ }^{15}$ Vid. Paulino CAPDEBÓN, El P. Antonio Soler y el cultivo del villancico en El Escorial, Madrid, Ediciones Escurialenses del Real Monasterio de El Escorial, 1993 (Biblioteca de la Ciudad de Dios, 59), p. 35. 
un ejemplo de esta práctica en la catedral de Granada donde su primer arzobispo, Hernando de Talavera, introdujo la novedad de cantar algunos textos e incluso de hacer alguna pequeña representación relacionada con ellos:

En lugar de responsorios hacía cantar algunas coplas devotísimas correspondientes a las liciones. Desta manera atraía el santo varón a la gente a los maitines como a la misa. Otras veces hacía hacer algunas devotas representaciones, tan devotas que eran más duros que piedras los que no echaban lágrimas de devoción ${ }^{16}$.

Se ha señalado que muchas de las piezas cantadas en las que intervienen varios personajes poseen «una clara configuración dramática» ${ }^{17}$. Es importante referirnos en este punto a las églogas de Juan del Encina, piezas dramático-musicales protagonizadas por pastores, destinadas a ser representadas como complemento a la liturgia o como base de festejos cortesanos, aunque imitan un estilo popular. Alfredo Hermenegildo señala que son precisamente esas églogas pastoriles, algunas de tema navideño, las obras que pueden considerarse «la plataforma desde la que se inicia la trayectoria del teatro en lengua castellana» ${ }^{18}$. El mismo autor, en otro estudio, establece una sugerente relación entre el personaje del pastor, del primitivo teatro castellano, que nace ligado a la liturgia, y la figura del gracioso de tanto peso en el teatro clásico ${ }^{19}$.

La costumbre de cantar ciertos textos surge, por tanto, de forma paralela a la de representarlos añadiéndoles algo más hasta llegar a ser pequeñas obras teatrales de tema religioso, muy en especial navideño, práctica que llegará a tener un amplio arraigo. Por lo menos a partir del siglo $\mathrm{XV}$, se hacen frecuentes «en las celebraciones de la Navidad popular, por un lado, las representaciones dramáticas propiamente tales, $\mathrm{y}$ por otro, estos textos cantados, que alguna vez llegaban a incluir una pequeña tramoya y escenas» ${ }^{20}$ y que ya empiezan a llamarse villancicos independientemente de que lo sean o no métricamente.

Por cierto que Cervantes en Don Quijote, proporciona un curioso testi-

${ }^{16}$ Breve Suma de la santa vida del Reverendísimo y Bienaventurado don fray Hernando de Talavera. Ms de la Academia de la Historia (Signatura 9-25-6, c, n ${ }^{\circ} 114$, Fol.149v) (Apud. Paulino CAPDEBÓN, loc. cit., pp. 35-36).

17 Vid. José Carlos GonZÁlez BoIXo (ed), Sor Juana Inés de la Cruz, Poesía Lírica, Madrid, Cátedra, 1992, p. 42.

18 Vid. Antología del teatro español del siglo XVI. Del palacio al corral, Edición de Alfredo Hermenegildo, Madrid, Biblioteca Nueva, 1998, p. 21.

19 Vid. Alfredo HERMENEGILDO, Juegos dramáticos de la locura festiva. Pastores, simples, bobos y graciosos del teatro clásico español, Madrid, Oro Viejo, 1995.

${ }^{20}$ José Luis AlONSO PONGA, Religiosidad popular navideña en Castilla y León. Manifestaciones de carácter dramático, Consejería de Educación y Cultura de la Junta de Castilla y León, 1986, p. 19. 
monio de estas costumbres: «...murió esta mañana aquel famoso pastor estudiante llamado Grisóstomo... Olvidabaseme de decir cómo Grisóstomo, el difunto, fue grande hombre de componer coplas tanto, que él hacía los villancicos para la noche del Nacimiento del Señor y los autos para el día de Dios, que los representaban los mozos de nuestro pueblo...» ${ }^{21}$

De esta práctica, que llegó a tener fuerte arraigo en muchas áreas de la Península, se lamentarán los ilustrados del siglo XVIII a quienes resultaba vulgar, inculta e incluso de mal gusto ${ }^{22}$.

\section{VILLANCICOS, CANCIONES NAVIDEÑAS Y PASTORELAS ${ }^{23}$}

El villancico, que es una forma poética de raíz popular, fue en la Edad Media el tipo de canción más usual y tuvo también gran popularidad en el siglo XVI y durante el Barroco. Se trata de una composición de versos de arte menor (octosílabos y hexasílabos) que tiene dos partes: estribillo y pie $^{24}$. Sin embargo, el villancico por su extenso cultivo y amplia aceptación presentará más adelante una enorme variación en cuanto a la forma.

Sobre los temas que trata esta composición poética, Quilis explica: «El villancico, en sus épocas de mayor esplendor, se empleó tanto en temas devotos, de la Natividad preferentemente (no olvidemos que sus antecedentes parecen ser los cantos litúrgicos de la Iglesia Católica), como profanos, en cantares de pastores y zagalas en los que se trataba el tema de

${ }^{21}$ Miguel DE Cervantes, Don Quijote de la Mancha. Edición del Instituto Cervantes dirigida por Francisco Rico, Barcelona, Crítica, 1998, parte I, cap. XII, p. 128, lín. 8-9 y p. 130, lín. 10-14.

${ }^{22}$ Alonso PONGA, op.cit., pp. 20-21.

${ }^{23}$ El término pastorela tiene, al menos, dos acepciones, aunque una de ellas - a la que nos referimos en este trabajo- no suele aparecer en los diccionarios de términos literarios ni en tratados sobre géneros literarios. Demetrio Estébanez Calderón (Diccionario de términos literarios, Madrid, Alianza, 1996, s.v. pastorela) recoge el término pastorela como «procedente del occitano pastorela (pastorcilla), con el que se designa una composición lírica de origen provenzal, cuyo tema es el encuentro de un caballero con una pastora a la que él intenta seducir». Se trata de una composición de carácter culto y es el antecedente de las serranillas de la lírica castellana. Sin embargo, no menciona que el mismo término, junto a otros varios como pastorada, corderada etc., se han usado en España desde antiguo, para designar un tipo de obrita teatral de carácter muy popular, cuyo tema es la adoración de los pastores al Niño Jesús y su destino ser representada por pastores la noche de Navidad. Como vamos a ver, en. México y otros países de Hispanoamérica, la voz pastorela que designa este tipo de representaciones es un vocablo de uso totalmente general y prácticamente unívoca, pues designa exclusivamente este tipo de representaciones.

${ }^{24}$ Vid. Miguel Ángel GARRIDO GALlaRDo, Nueva introducción a la teoría de la literatura, Madrid, Síntesis, 2000, p. 271, también Antonio QUILIS, Métrica española, Barcelona, Ariel, 2001, p. 128 y Domínguez CAPARRós, op.cit., p. 217 y ss. 
la belleza femenina o temas de la naturaleza» ${ }^{25}$. Precisamente en este punto, está el origen de su nombre: villancico (y sus variantes arcaicas villancejo, villancete) es diminutivo de villano, 'aldeano', 'rústico' y 'los cantares propios de él'. Era por tanto, en un principio, toda canción o diálogo pastoril ${ }^{26}$.

Los motivos y expresiones que encontramos en las canciones navideñas españolas tradicionales son muy parecidos a los del texto de las Marianas. Podemos ver algunos ejemplos como el siguiente fechado en 1746:

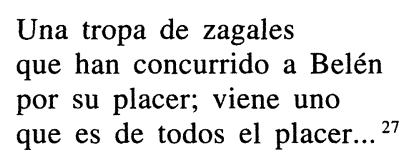

O también en este otro, en forma de diálogo, en el que es evidente la posibilidad de ser interpretado y resulta clara la relación con formas representadas. Además, utiliza el nombre de pastorela para definir la composición que canta y adopta la forma métrica del romancillo hexasilábico:

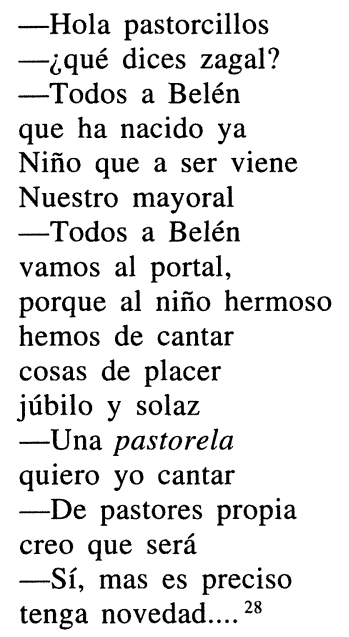

Así también, encontramos versos parecidos y la utilización de motivos semejantes en textos navideños conservados en la catedral de Córdoba. El ejemplo que aducimos pertenece a las «Letras de los uillancicos que se

${ }^{25}$ Vid Antonio QuILIS, op. cit. p. 128.

26 Vid. Alfonso MÉNDEZ Plancarte (ed), Obras completas de Sor Juana Inés de la Cruz Tomo II. Villancicos y Letras Sacras, México, Fondo de Cultura Económica, 1952, p. XI.

27 José L. Palacios Garoz, El último villancico barroco valenciano, Castellón, Diputació de Castelló y Universitat Jaume I, 1995 (Biblioteca de les aules, 1), p. 386.

${ }^{28}$ Ibid, p. 383. 
han de cantar en los maytines del nacimiento de N. S. Jesvchristo en la Santa Iglesia Catedral de Córdoba este año de 1696 puestos en música por el Licenciado don Juan Pacheco...»:

Los zagales alentados

Al nuevo tropel se inclinan

$Y$ a ver al Niño caminan

De pobres dones cargados... ${ }^{29}$

En la provincia de León, Joaquín Díaz y José Luis Alonso Ponga ${ }^{30}$ recogen entre otros muchos el siguiente texto:

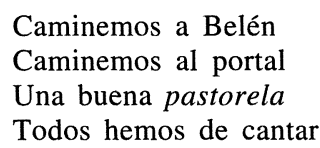

Vemos, por tanto, que el término empleado para este tipo de cantos u obritas teatrales era pastorela. En ocasiones, se le da otros nombres como el de pastorada o corderada, propios de la zona de León. Estas pequeñas obras teatrales consistían en la representación del pasaje evangélico de la adoración de los pastores: «Unos pastores velan sus rebaños; muertos de frío protestan del tiempo y de la escasez de los pastos; hacen unas migas, se calientan al fuego y alaban sus pobres viandas; mientras los demás duermen, el pastor que vela oye la voz de un ángel que les anuncia el nacimiento de un Niño; despierta a sus compañeros para comunicarles la nueva; protestan, discuten y no le creen; hasta tres veces ha de repetir el ángel su anuncio; por fin, decididos, abandonan los rebaños, van a Belén, adoran al Niño y le ofrecen los dones típicos de su condición» ${ }^{31}$.

Transcribimos a continuación otro fragmento de pastorela recogido en la provincia de Palencia por Díaz y Alonso Ponga ${ }^{32}$ que guarda un paralelismo muy claro con el texto de las Marianas:

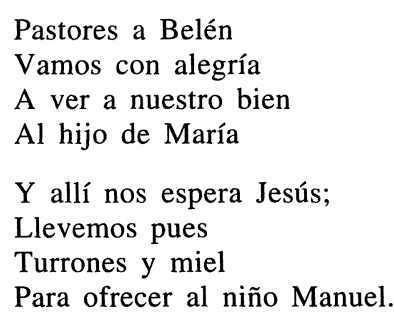

${ }^{29}$ Rafael Bonilla e Ignacio García Aguilar, Villancicos de la Catedral de Córdoba 1682-1767 Métricas cadencias clarines sean, Córdoba, Ediciones La Posada, 2002, $206 \mathrm{pp}$.

${ }^{30}$ Autos de Navidad de León y Castilla, León, Santiago García, 1983, p.134.

${ }^{31}$ Maximiano TRAPERo, La pastorada leonesa. Una pervivencia del teatro medieval, Madrid, Sociedad Española de Musicología, 1982, p. 45.

${ }^{32}$ Vid DíaZ y AlOnso PONGA, op.cit., p. 146. 
La transmisión oral sería el primer rasgo de estos autos leoneses que, según expone Trapero, han seguido vivos hasta nuestros días ${ }^{33}$.

\section{Pastorelas y Canciones navideñas en MéXico y Filipinas}

En una amplia zona que incluye México, América Central, Sur de Estados Unidos y Filipinas se cultiva intensamente este tipo de representación navideña con el nombre de pastorela o pastores. En diversos diccionarios que recogen el término en México ${ }^{34}$ se especifica que también aparecen idénticos términos con iguales significados en Honduras ${ }^{35}$ y Nicaragua $^{36}$. En el Sur de Estados Unidos se recogen las formas pastorela, pastores o Los pastores con el mismo significado ${ }^{37}$. En Filipinas aparecen el término pastoras en bicolano y pastorela y pastorales en tagalo ${ }^{38}$.

33 «...las gentes de los pueblos donde la tradición se conserva hablan de ella como de algo propio y muy querido, pero ... en todos ellos se manifiesta, ya de forma generalizada y sobre todo en los pastores más viejos y depositarios de la tradición, una nostalgia no disimulada de aquellos otros tiempos en que las representaciones eran brillantes, multitudinarias y asiduas. Sigue siendo pues una tradición viva pero cada vez se representa menos y en menos pueblos, y sólo en aquellos en donde vive un viejo pastor que la sabe de memoria. Y ello por dos causas fundamentales: porque los pastores en ejercicio por estas tierras son cada vez menos y porque al no haber pastores suficientes en el pueblo para interpretar todos los personajes de la obra ha de recurrirse a otros intérpretes, en este caso agricultores, que no están dispuestos a tomar parte en una tradición que desde que hay memoria ha estado en manos de pastores» (ibid, pp. 26-27).

${ }^{34}$ Vid. Marcos A. MORÍNIGO, Diccionario de americanismos, Barcelona, Muchnik Editores, 1985; Francico J. SANTAMARÍA, Diccionario de mejicanismos, Méjico, Porrúa, 1983 y Ranaud RICHARD (coord.), Diccionario de hispanoamericanismos no recogidos por la Real Academia, Madrid, Cátedra, 1997, s.v. pastorela.

${ }^{35}$ Así lo señalan Marcos A. MORÍNIGO, op. cit. y Renaud RiCHARD, op. cit. ( $s v$. pastorela y pastores).

${ }^{36}$ Vid Francisco J. SANTAMARÍA, op. cit. (s.v. pastorela).

37 Vid. Rubén CoBos, A dictionary of New Mexico and Southern Colorado Spanish. Santa Fe, Museum of New México Press, 1983, s.v. pastorela («Mex. Sp. Pastorela shepherds'play also known as Los pastores, a dramatic presentation in which shepherds go to Bethlehem to offer gifts to the Christ Child» y s.v. pastores ( «Los pastores. See pastorela»).. Vid. también Roberto A. GALVÁN y Richard V. TESCHNER, El diccionario de español chicano. The dictionary of Chicano Spanish, Lincolnwood, Illinois, National Textbook Company, 1989 (ed. 1994) que parece introducir una diferencia de significado entre los dos términos recogidos: s.v. pastorela («Traditional theatrical representation of the birth of Christ performed around Christmas time») y s.v pastores, («Los pastores. Traditional Christmas pastoral play which depicts the visit of the shepherds to the stable at Bethlehen»).

38 Vid Malcolm WARREN MINTZ y José DEL Rosario BRITÁNICO, Bikol-English Dictionary, Quezon City, New Day Publishers, 1985, s.v. pastoras ( $«$ A religious play in which the shepherds are shown spreading the news of Christ's birth, performed from Christmas Day to January 6»). Adolfo CUADRADo MUÑIZ, Hispanismos en el tagalo, Madrid, Oficina de Educación Iberoamericana, 1972 recoge las voces pastorales y pastorela. 
En todas ellas, van insertos textos similares en el contenido y la expresión al conservado en las islas Marianas. Es el caso de la Pastorela del Ermitaño, obra mexicana recogida por Miguel Sabido ${ }^{39}$ que intercala reiteradamente esta copla (7_ 6 a $7_{-} 6$ a):

$$
\begin{aligned}
& \text { Vamos pastores vamos } \\
& \text { Vamos a Belén } \\
& \text { A ver en ese niño } \\
& \text { Las glorias del Edén }
\end{aligned}
$$

En la Pastorela de Bartolo y Carrasquilla ${ }^{40}$ se intercala varias veces esta misma copla y algunas más del mismo tema como la siguiente:

$$
\begin{aligned}
& \text { A Belén pastores } \\
& \text { Todos a Belén } \\
& \text { A ver a la Virgen } \\
& \text { y al niño también } \\
& \text { Hoy nace ese niño } \\
& \text { que nos va a salvar } \\
& \text { a Belén pastores } \\
& \text { vamos a adorar... }
\end{aligned}
$$

En esta misma pastorela aparece el motivo de la belleza de la noche del nacimiento que está también presente en el texto que estudiamos:

$$
\begin{aligned}
& \text { Cuán hermosa está la noche } \\
& \text { reverberan las estrellas } \\
& \text { cuán hermosa está la noche } \\
& \text { reverberan las estrellas } \\
& \text { reverberan las estrellas... } \\
& \text { y al fijar la vista en ellas } \\
& \text { siento el corazón latir... }{ }^{42}
\end{aligned}
$$

La copla («vamos pastores vamos»), repetida en varios momentos, aparece, asimismo, en la Pastorela de Sor Juanita ${ }^{43}$ que inserta además este romancillo hexasilábico atribuido a Sor Juana Inés de la Cruz, que es la Sor Juanita que aparece en esta representación:

$$
\begin{aligned}
& \text { Pastores amigos } \\
& \text { Con grandes afectos } \\
& \text { Vámonos alegres } \\
& \text { A tanto festejo } \\
& \text { Al golpe del agua }
\end{aligned}
$$

\footnotetext{
${ }^{39}$ Miguel SABIDo, El libro de las pastorelas, México, Instituto Mexicano de Estudios para la Comunicación, 2000, pp. 216 y ss.

${ }^{40}$ Ibid. pp. 35 y ss.

${ }^{41}$ Ibid., p. 85.

${ }^{42}$ Miguel SABIDO, op. cit., p. 48.

43 Ibid., pp. 109 y ss.
} 
$\mathrm{Y}$ al silbo del viento

Al son de las hojas

$\mathrm{Y}$ al ruido del eco... ${ }^{44}$

El tema de la invitación de los pastores a ir a Belén se repite continuamente en las canciones navideñas populares mexicanas:

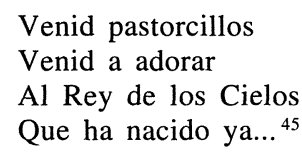

O también en este otro ejemplo, igualmente mexicano:

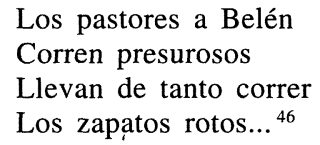

$\mathrm{Y}$ encontramos rasgos semejantes en este otro ejemplo:

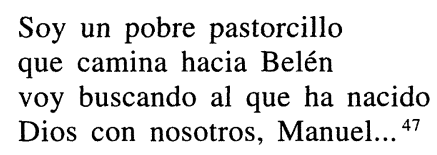

Desde México y a través del galeón que unía Acapulco con Manila, llegó a Filipinas una serie interminable de manifestaciones culturales propias de México que arraigaron, en ocasiones reinterpretadas, en Filipinas: hubo una auténtica transculturación entre México y las islas. Como señala Rafael Bernal, «las rutas del comercio no sirven tan sólo para llevar mercaderías. Llevan también hombres y, con los hombres, [se transmiten] las ideas, las palabras, las maneras de vida, las artesanías y las artes» ${ }^{48}$.

En Filipinas, subsisten también formas del teatro misionero navideño que tienen una tradición extensa y cuyo origen hay que buscarlo en la época virreinal. Todavía hoy en varias provincias entre ellas las bicolanas de $\mathrm{Ca}$ marines Sur y Albay se celebran este tipo de representaciones que se conocen con el nombre de pastores o pastorelas y que consisten en bailes y cantos de grupos de jóvenes disfrazados de pastores que cantan, acompañados de instrumentos, canciones navideñas en bicolano y en español ${ }^{49}$, algu-

${ }^{44}$ Ibid., p. 139.

${ }_{45}$ Cancionero popular mexicano, Tomo 2. Selección, recopilación y textos de Mario Kuri-Aldana y Vicente Mendoza Martínez, México, Consejo Nacional para la Cultura y las Artes, 2001, p. 168.

46 Ibid., p. 174.

${ }^{47}$ Cancionero popular..., p. 166.

${ }^{48}$ Rafael Bernal, México en Filipinas. Estudio de una transculturación, México, Universidad Nacional Autónoma de México, 1965, p. 109.

49 Vid. Nicanor G. TIONGSON, «Mexican-Philippine Relations in traditional Folk Theater» Philippine Studies, vol. 46, 1998, pp. 135-142. 
nas de las cuales guardan un paralelismo claro con la que estudiamos. Así por ejemplo, la siguiente composición, en español, recogida por Tiongson:

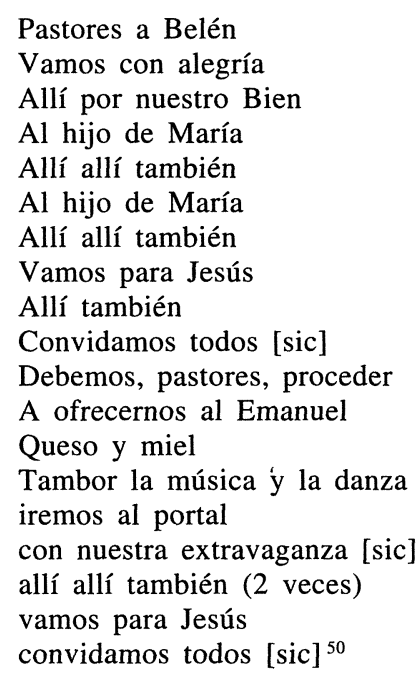

A pesar de la dudosa transcripción se puede apreciar que el parecido con el texto de las Marianas es evidente e incluso usa las mismas palabras («Emmanuel, queso y miel...»). Ello nos hace pensar en la posibilidad de un origen común. Estamos ante las manifestaciones más apartadas de la amplia zona de difusión de la pastorela hispana.

Teniendo en cuenta la relación de las Marianas con Filipinas y México y la vinculación que existió entre la evangelización de América y la de las Islas del Poniente ${ }^{51}$ parece evidente que durante siglos hubiera un trasvase de textos entre las diferentes regiones del mundo hispánico. Los misioneros españoles o mexicanos que iban a Filipinas y Marianas probablemente

\footnotetext{
${ }^{50}$ Nicanor TIONGSON (op. cit., p. 141-142) hace la transcripción de este texto. No hay que olvidar que también en Filipinas el español tiene una situación de lengua residual y este tipo de mensajes de lenguaje repetido se reproducen sin comprender ya exactamente lo que se dice. Ello explica los errores y vacilaciones de algunas transcripciones. Tiongson atribuye la composición a José Rizal, aunque, según puede comprobarse, no aparece en las poesías completas de Rizal editadas por Nick Joaquín (The Complete Poems and Plays of José Rizal, [Manila], Far Eastern University,1976.

${ }_{51}$ Toda esta zona recibió desde el siglo XVI el nombre de «Indias del Poniente» o «Islas del Poniente». La razón de este nombre histórico está en que para navegar desde México a Filipinas hay que navegar hacia el Poniente: los galeones salían de Acapulco y emprendían rumbo hacia el Oeste, hacia el Poniente. Esta designación, meramente geográfica, en un principio, acabó siendo un nombre propio. Sobre ello, vid. Paloma Albalé, Americanismos en las Indias del Poniente. Voces de origen indígena americano en las lenguas del Pacífico, Frankfurt, Madrid, Vervuert, Iberoamericana, 2000, pp. 19-20.
} 
llevaran aprendidas, o pseudoaprendidas, algunas de estas obritas y varias de estas canciones. En ocasiones, quizá, las compondrían de nuevo o las recrearían recordando en parte las ya conocidas.

La pastorela arraigó en México y en amplias zonas de América Central desde la época virreinal y es todavía hoy algo muy vivo, parte obligada de todas las celebraciones navideñas de estos países.

La pastorela mexicana incluye con respecto a las que hemos visto en la Península, nuevos motivos. Según el estudioso mexicano Romero Salinas ${ }^{52}$ el asunto de estas representaciones navideñas es invariablemente el deseo de los pastores de llegar a Belén para adorar al niño Jesús y el impedimento por parte de Luzbel y sus huestes - normalmente representadas por los siete pecados capitales- que, con ello, trata de evitar la salvación de esos hombres. Aparece en ese punto el arcángel San Miguel y libra su batalla contra el Demonio, de la que resulta vencedor, permitiendo así que los pastores lleguen a Belén y hagan sus ofrendas. El mismo autor, hecha la salvedad de la gran diversidad existente, aporta el siguiente esquema o estructura de este tipo de representación ${ }^{53}$ :

- loa o presentación

- caminata con cantos y bailes

- coros

- diálogos de diablos

- diálogos de pastores

- petición de posada por José y nacimiento en el pesebre en una gruta

- diálogos de retención entre pastores y diablos

- lucha entre San Miguel y el diablo

- llegada a Belén y adoración (canciones navideñas)

- ofrecimiento (canciones navideñas)

- despedida con cantos y bailes

El origen de este género tan popular hay que buscarlo en las primeras etapas de la evangelización de México. El estudio de Romero Salinas aporta una serie de datos que interpreta - creemos - erróneamente de manera que llega a la conclusión de que la pastorela «fue creada, difundida y conservada por los jesuitas y los alumnos de sus colegios» ${ }^{54}$. Sin embargo, ya lo

\footnotetext{
52 Joel ROMERo SALINAS, La pastorela mexicana, origen y evolución, México, Fondo Nacional para el Fomento de las Artesanías, Fonart, [1984], p. 13.

${ }^{53}$ Idem. Otro intento de plasmar la estructura de la pastorela lo hace Miguel Sabido (op. cit, pp. 29-30) basándose en la estructura tonal de las diferentes partes, enfrentando el tono lírico de las caminatas de los pastores con el tono de farsa de los diablos. Las conclusiones de los dos autores son muy parecidas.

${ }^{54}$ Romero Salinas, loc. cit. p. 54. Este dato puede resultar curioso porque en las Marianas la primera evangelización se llevó a cabo por jesuitas, desde que el P. Diego
} 
hemos visto, la creación no es ni jesuita ni se lleva a cabo en América sino que tenía ya un claro arraigo popular en España.

Los franciscanos, primeros artífices de la evangelización de México ${ }^{55}$, fueron los primeros en usar el teatro como medio de evangelización ${ }^{56}$. Como señala Othón Arróniz ${ }^{57}$, en torno a 1533 , cuando aparecen los primeros intentos de representación, es un momento en el que en España el teatro no había llegado al desarrollo y la importancia que décadas más tarde tendría con Lope y Calderón. Por otra parte, el teatro cortesano y palaciego, muy minoritario, poco podía influir en los conventos franciscanos. En realidad, lo que hicieron estos misioneros fue transmitir unas formas escénicas muy populares que habrían presenciado en sus lugares de origen en España y las pusieron al servicio de la tarea que habían de cumplir: la evangelización.

A los franciscanos corresponde, por tanto, el mérito de la introducción del teatro de evangelización, pero es cierto que no lo cultivaron de una manera continuada y, en cuanto a su temática, se centraron más en ejemplificaciones y representaciones del Corpus Christi, y, dentro del tema navideño, demostraron una preferencia declarada por la epifanía, tema que tiene también amplia y muy antigua tradición de representación popular en España ${ }^{58}$. De esta forma, la representación de la adoración de los Reyes Magos todavía se conserva hoy en México como la adoración del «Niñopa» en

Luis de Sanvitores SJ llegara a las islas en 1668 con cinco jesuitas más y fundara la primera misión de la zona como se ha señalado más arriba. Durante siglos fue esta orden la que tuvo mayor presencia en la región hasta que acaeció, en 1767, la expulsión de la Compañía de Jesús de todos los territorios españoles, momento en que, en las islas fueron sustituidos por agustinos (Vid. Francis X HEZEL, SJ, From Conquest to colonization: Spain in the Mariana Islands 1690 to 1740, Saipan, Division of Historic Preservation, 1989, 90 pp.).

${ }^{55}$ En el año 1524 llegan a México, por petición expresa de Hernán Cortés, los primeros doce misioneros de América que eran franciscanos (vid. Gerónimo DE MENDIETA, Historia Eclesiástica Indiana, Estudio preliminar y edición de Francisco de Solano y Pérez Lila, 2 tomos, Madrid, Atlas, 1973, p. 129).

${ }^{56}$ Othón Arróniz, estudioso del teatro de evangelización en México afirma que sólo nueve años después del desembarco de los primeros doce evangelizadores del Nuevo Mundo ya hay menciones de representaciones teatrales religiosas. La primera obra mexicana conocida fue la representación de un Ejemplo («Nexcuitilli») sobre el castigo a los culpables de bigamia. Era una representación que empleaba toda una serie de recursos de la tramoya medieval: «muy probablemente no fue sino una forma dialogada de lo que manifestaban los sacerdotes españoles en sus Doctrinas bilingües» (Teatro de evangelización en Nueva España, México, Universidad Nacional Autónoma de México, 1979, p. 30).

${ }^{57}$ Ibid., p. 16.

${ }^{58}$ Precisamente la más antigua obra conservada - fragmentariamente - del teatro medieval castellano es el Auto de los Reyes Magos (Vid. Fernando LÁZARo CARrETER, op. cit., pp. 31-34). 
Xochimilco ${ }^{59}$ y tiene, con seguridad, su origen en la evangelización franciscana.

Ahora bien, en 1572 llegan los jesuitas a México cuyo principio evangelizador tenía un matiz algo distinto: los jesuitas trataban de preparar al joven mediante una extensa y variada educación que le permitiera tomar una posición firme en la vida para defender los aspectos más dogmáticos de su religión, la finalidad era crear un «soldado de Cristo» ${ }^{60}$. Para ello, recurrían a la figura de San Miguel, el soldado de Dios vencedor del Diablo, que es personaje central de toda pastorela mexicana. El motivo repetido en todas estas piezas es, precisamente, la lucha del arcángel contra Luzbel, alegoría de la lucha del hombre con el pecado que tiene amplio arraigo en la tradición pedagógica de los jesuitas.

Sin embargo, no es posible adjudicarles sólo a ellos el cultivo y la difusión de las pastorelas en. México. Mas bien, las recrearon de acuerdo con sus propios enfoques e intereses pedagógicos pero la difusión de estas representaciones la llevaron a cabo miembros de las distintas órdenes que participaron en la evangelización de América y del Poniente. De hecho, en las provincias bicolanas de Filipinas donde hoy encontramos vivas las pastorelas y donde hemos hallado uno de los textos con más paralelismos con el que estudiamos, la evangelización no estuvo nunca a cargo de jesuitas.

Lo que también es cierto es que en América, la pastorela trascendió las límitaciones con que había nacido en la Península. Como instrumento al servicio de un fin destinado a todos por igual, la evangelización, conoció una ampliación considerable tanto en el destinatario como en los encargados de representarla que no serán ya un grupo único como el de los pastores. De hecho, hoy esta tradición sigue muy viva en México y otros muchos puntos de Hispanamérica y se representa continuamente en las fechas apropiadas en todo tipo de ambientes y por todo tipo de personas.

\section{PERVIVENCIA DE LAS CANCIONES ESPAÑOLAS EN LAS ISLAS MARIANAS}

La canción navideña que aquí editamos y estudiamos, conservada hasta hoy en las Marianas no es un hecho aislado ${ }^{61}$. En el grupo de población autóctona de las Marianas ${ }^{62}$ todavía hoy existen personas que aprendieron

\footnotetext{
${ }^{59}$ Romero Salinas, op. cit., p. 32.

${ }^{60}$ Ibid., p. 33.

${ }^{61}$ Vid Paloma Albalá, «Canciones españolas en las Islas Marianas», en Dolores ElizALDE, ed., Imperios y naciones en el Pacífico, Filipinas, Micronesia y otros espacios, Madrid, CSIC, 2001.

${ }^{62}$ Hoy en las islas existe una gran diversidad étnica y una fuerte inmigración procedente de otros archipiélagos vecinos y de varios países asiáticos (Filipinas, China, Corea,
} 
el español en su infancia por las vías tradicionales de adquisición. En las islas, no hubo nunca un grupo de población autóctona que tuviera el español como lengua materna, y por tanto, las vías de adquisición fueron otras: el mestizaje y la evangelización fundamentalmente. Éstas no quedaron interrumpidas de manera definitiva cuando las Marianas dejaron de ser españolas. Concretamente, la evangelización continuó porque los misioneros españoles siguieron presentes en toda la zona e instruyeron - parcialmente, y solo en materias religiosas- en español. De esta forma, todavía hoy es posible encontrar chamorros que aprendieron el español durante su infancia en las llamadas «escuelan pa 1 le» ${ }^{63}$. Hace años tuve la oportunidad de grabar en las propias islas a varios de estos informantes ${ }^{64}$. Entre ellos, la situación dista mucho de ser uniforme, pero nuestras encuestas sí permiten ver que el español en las Marianas, ya en 1985, era lo más parecido a un resto arqueológico de la variedad de éspañol que se habló en las islas y que nunca fue descrito, pero que, muy probablemente, sería parecido a la variedad de español hablado en Filipinas que ha estudiado Antonio Quilis ${ }^{65}$.

La situación del español en las Marianas, que es la de una lengua residual, es paralela a la de otros puntos geográficos donde nuestra lengua estuvo suficientemente extendida y después diversos cambios, sobre todo de tipo político, la hicieron replegarse ante otra lengua. Es el caso del español de Orán estudiado por Francisco Moreno ${ }^{66}$ y del español de Trinidad estudiado por Moodie ${ }^{67}$, quien afirma que «el español funciona en la

Japón...). Además en las islas hay importantes bases militares de Estados Unidos por lo que hay una presencia continuada y abundante de estadounidenses. En este marco social permanece un grupo - claramente diferenciado- de población autóctona, los chamorros. En las islas viven hoy unos 50.000 chamorros que conservan su lengua autóctona y una serie de rasgos propios, muchos de ellos debidos a la herencia hispana que definen y singularizan su vida en el contexto en que se desenvuelve.

${ }^{63}$ Las Escuelan pa'le eran las 'Escuelas de los padres, de los sacerdotes'. Pa'le es la adaptación fonética chamorra del español padre, con simplificación del grupo consonántico, sustitución de la líquida vibrante por la lateral y ataque glotal característico de las lenguas malayopolinésicas representado gráficamente por la coma volada. La palabra pa'le es uno de los hispanismos más antiguos en chamorro.

${ }^{64}$ Las conclusiones y el estudio que realicé aparecen en Paloma ALBALÁ, «El español de los chamorros de las Islas Marianas», Español Actual, núm. 68, 1997. pp. 63-74.

${ }^{65}$ Vid Antonio Quilis, «La huella lingüística de España en Filipinas», en Arbor, 1975, 353, pp. 21-37; y también La lengua española en Filipinas. Estado actual y directrices para su estudio, Valladolid, Universidad, 1992.

${ }^{66}$ «El español de Orán: notas históricas, dialectales y sociolingüísticas», Revista de Filología Española, LXXII, 1992, pp. 5-35.

${ }^{67}$ Sylvia María MoodiE, «The phonemic system of the Spanish of Trinidad», Caribbian Studies, 13, 1973, pp. 95-98; «Trinidad Spanish pronouns: a case of language death in the Caribbean» en R Nash y otros, eds, Readings in Spanish English Contrastive Linguistics, InterAmerican University, 1982, pp. 206-228 y «Examen del léxico de un dialecto obsolescente: el español de Trinidad», Actas del Congreso Internacional del español de América, San Juan de Puerto Rico, 1987, pp. 593-599. 
sociedad trinitaria como lengua de los aguinaldos cantados en las parrandas navideñas» ${ }^{68}$. También se ha descrito el fenómeno del español residual en las zonas de los estados del Sur de Estados Unidos que fueron mexicanas hasta 1848 y en las Filipinas ${ }^{69}$.

Este español residual de las Marianas se caracteriza por una fonética muy próxima a la de la lengua autóctona, el chamorro, una clara tendencia a la simplificación y a la reducción morfosintáctica y un léxico con gran cantidad de interferencias del chamorro y del inglés.

En cualquier caso, entre los chamorros, podemos encontrar personas de situación y edades variadas, que pueden reproducir plegarias, jaculatorias, canciones y oraciones aprendidas en la niñez. Por varias razones, entre ellas el prestigio de la lengua española y la tendencia conservadora del culto, se han conservado sólo canciones religiosas, entre ellas Pastores a Belén ${ }^{70}$.

Este texto y otros de características parecidas conservados en las islas Marianas, constituyen el último reducto en el que se conserva, entre los chamorros, el español estándar. Precisamente es su condición de «mensaje literal» ${ }^{71}$ que le confiere una estructura fija, no alterable por principio, lo que ha garantizado su pervivencia. Hay que advertir que los chamorros que pueden reproducir esta clase de secuencias no comprenden todo lo que dicen, pues lo hacen de manera parecida a como se puede cantar hoy en España, por ejemplo, el Adeste Fideles en latín. Las familias chamorras, actualmente, siguen cantando en la época de Navidad Pastores a Belén y lo consideran absolutamente propio. Es quizá esta canción uno de los últimos testimonios de una fidelidad lingüística difícilmente mantenida.

${ }^{68}$ Vid. Sylvia María Moodie, «El español de Trinidad: variabilidad y desgaste articulatorio», Anuario de Lingüística Hispánica, 2, 1986, p. 194.

${ }^{69}$ Vid. John LIPSKI, «El español vestigial en los Estados Unidos: caracteríticas e implicaciones teóricas», Estudios Filológicos, 21, 1986, p. 9 y «El español en Filipinas: comentarios sobre un lenguaje vestigial», Anuario de Lingüística Hispánica, III, 1987.

${ }^{70}$ En nuestra búsqueda en las islas no encontramos canciones españolas de tema no religioso, pero es seguro que en épocas no lejanas se cantaron y recitaron romances y poemas en español, semejantes a los que en Filipinas se conocen con el nombre de corridos (vid. Damiana, L. Eugenio, Awit and Corrido, Philippine Metrical Romances, Quezon City, University of the Philippine Press, 1987). En 1953, Francisco Ramón Espinosa («Folklore español de la isla de Guam», Revista de Dialectología y tradiciones populares, Madrid, núm. 122, 1953, pp. 55-125) dio a conocer el hallazgo de dos manuscritos de Guam en el que se transcribían dos romances españoles: uno es de tema carolingio, el romance de Valdovinos, el otro trata de Lucinda y Velardo en la Corte del Gran Sultán.

${ }^{71}$ «Llamamos lenguaje literal al empleado en comunicaciones que deben ser descifradas en sus propios términos y que así deben conservarse» (Fernando LÁZARo CARRETER, «El mensaje literal», en Estudios de Lingüística, Barcelona, Crítica, 1980, p. 16). 


\section{CONCLUSIÓN}

La canción navideña Pastores a Belén y otros textos conservados en las islas Marianas son un exponente de la hispanización que se llevó a cabo en las islas desde el siglo XVI y de la evangelización iniciada en 1668 por el jesuita Diego Luis de Sanvitores. Lingüísticamente hemos de entenderlo enmarcado dentro de lo que podemos considerar una huella residual del castellano: el español de las Marianas. Este breve texto es como un «resto arqueológico» de la literatura española en estas lejanas islas.

En cuanto a su filiación y procedencia concretos, podemos asociarlo, por su estructura y tema, con algunas manifestaciones populares de antigua tradición en la Península, después difundidas por los misioneros en todo el enorme dominio hispánico, conocidas como pastorelas. El texto que estudiamos puede ser una canción aislada, siempre con la posibilidad de ser escenificada, o bien el fragmento de una obrita de teatro, de una pastorela. En cualquier caso, se trata de un mismo asunto: composiciones de tema navideño con pastores como protagonistas para recitar, cantar o escenificar en unas determinadas fechas que entroncan con una tradición antigua española, mexicana y podríamos decir panhispánica. Las pastorelas y canciones navideñas se difundieron, «fueron y vinieron» por todo el ámbito hispánico, en gran parte transmitidas por los misioneros que iban de unas zonas a otras. Es muy difícil, por no decir imposible, precisar cuál fue la vía de difusión de un texto concreto. Hay que considerarlo más bien, la manifestación concreta de una tradición popular arraigada en España, difundida y enriquecida con nuevos motivos por los misioneros españoles en todo el virreinato de México y transportada luego al Pacífico bien desde México hasta 1820, bien desde España. En cuanto a la época en que éste fue compuesto tampoco podemos conocer si se trata de una composición reciente o de siglos pasados, pero lo que es seguro es que recoge y recrea toda una tradición anterior.

Por último, podemos concluir que la existencia de este texto conservado en este último rincón de lo que fue el mundo hispánico refleja, como otras muchas manifestaciones culturales y artísticas, la posición intermedia no solo geográfica, sino también cultural, de las Islas Marianas con respecto a México y Filipinas, es decir, como zona indiscutiblemente adscrita al mundo hispánico. 


\section{RESUMEN}

Sobre la pastorela: a propósito de una canción navideña española en las islas Marianas, por Paloma Albalá.

El estudio y edición de un texto navideño español que se conserva en las Marianas, islas situadas en el Pacífico Norte que fueron españolas hasta 1898, lleva a establecer la relación de dicho texto con un tipo de composición literaria teatral de carácter muy popular, la pastorela, que conoció y conoce todavía hoy un amplio cultivo en México y otras zonas de América. Las composiciones que pueden adscribirse a este género fueron introducidas y difundidas en el Nuevo Mundo por los misioneros españoles que las utilizaron como instrumento de evangelización. Salvo en el rasgo de 'canción propia de pastores' esta pastorela tiene muy poco o nada que ver con la pastorela de origen provenzal y carácter culto de la que derivan las serranillas castellanas, que es el significado del término manejado por los estudiosos de la literatura.

La existencia de esta canción en las Marianas y de otros textos con él relacionados en las Filipinas así como la costumbre arraigada de cantar y representar este tipo de piezas en época navideña pone de relieve que aún en las zonas más distantes del ámbito hispánico hubo manifestaciones de esta tradición española, difundida y enriquecida con nuevos elementos en América y queda patente que todas ellas forman parte de la misma tradición literaria.

Palabras clave: Español residual; canción navideña; romance; pastorela; teatro misionero; tradición hispánica.

\section{ABSTRACT}

The study about a spanish Christmas Carol, preserved in Marianas, archipelago placed in North Pacific which were under spanish administration till 1898 , lead us to stablish a relationship between this text and a type of popular theatral composition, the pastorela, which had an important cultivation in Mexico and in some other areas of the two Americas. This kind of plays were introduced and spreaded by spanish missionaries who used it as an instrument of evangelization. Except for the feature 'carol sung by shepherds' this pastorela has very little to do with the pastorela of provenzal origin and learned character from which derives the castilian serranillas. This one is the most common meaning in literary studies.

The presence of this Christmas Carol in the Marianas and other similar texts in the Philippines as well as the custom of singing and performing these carols at Cristmas time reveals that yet in the furthest areas of Spanish influence had signs of this spanish tradition which was spreaded and enriched with new elements in America. It becomes clear that all of this expressions make part of the same literary tradition.

Key words: Vestigial spanish; Christmas Carol; ballad; pastorela; missionary theatre; spanish tradition. 